\title{
Reproductive health services for refugees by refugees in Guinea I: family planning
}

\author{
Natasha Howard*1, Sarah Kollie², Yaya Souare2, Anna von Roenne ${ }^{3}$, \\ David Blankhart ${ }^{3}$, Claire Newey ${ }^{1}$, Mark I Chen ${ }^{1}$ and Matthias Borchert ${ }^{1}$
}

\author{
Address: ${ }^{1}$ London School of Hygiene and Tropical Medicine (LSHTM), Keppel Street, London, UK, ${ }^{2}$ Reproductive Health Group (RHG), \\ Guéckédou, Guinea and ${ }^{3}$ Gesellschaft für Technische Zusammenarbeit (GTZ) GmbH, 65726 Eschborn, Germany \\ Email: Natasha Howard* - natasha.howard@lshtm.ac.uk; Sarah Kollie - aids.ms@gtz.de; Yaya Souare - yayaswaray@yahoo.com; Anna von \\ Roenne - anna.von.roenne@gmx.de; David Blankhart - dmblankhart@gmail.com; Claire Newey - claire_newey23@hotmail.com; \\ Mark I Chen - mark.chen@lshtm.ac.uk; Matthias Borchert - matthias.borchert@lshtm.ac.uk \\ * Corresponding author
}

Published: 16 October 2008

Conflict and Health 2008, 2:12 doi:10.1186/1752-1505-2-12
Received: 28 July 2008

Accepted: 16 October 2008

This article is available from: http://www.conflictandhealth.com/content/2/1//2

(c) 2008 Howard et al; licensee BioMed Central Ltd.

This is an Open Access article distributed under the terms of the Creative Commons Attribution License (http://creativecommons.org/licenses/by/2.0), which permits unrestricted use, distribution, and reproduction in any medium, provided the original work is properly cited.

\begin{abstract}
Background: Comprehensive studies of family planning (FP) in refugee camps are relatively uncommon. This paper examines gender and age differences in family planning knowledge, attitudes, and practices among Sierra Leonean and Liberian refugees living in Guinea.
\end{abstract}

Methods: In 1999, a cross-sectional survey was conducted of 889 reproductive-age men and women refugees from 48 camps served by the refugee-organised Reproductive Health Group (RHG). Sampling was multi-stage with data collected for socio-demographics, family planning, sexual health, and antenatal care. Statistics were calculated for selected indicators.

Results: Women knew more about FP, although men's education reduced this difference. RHG facilitators were the primary source of reproductive health information for all respondents. However, more men then women obtained information from non-health sources, such as friends and media. Approval of FP was high, significantly higher in women than in men ( $90 \%$ vs. $70 \%)$. However, more than $40 \%$ reported not having discussed FP with their partner. Perceived service quality was an important determinant in choosing where to get contraceptives. Contraceptive use in the camps served by RHG was much higher than typical for either refugees' country of origin or the host country ( $17 \%$ vs. 3.9 and $4.1 \%$ respectively), but the risk of unwanted pregnancy remained considerable (69\%).

Conclusion: This refugee self-help model appeared largely effective and could be considered for reproductive health needs in similar settings. Having any formal education appeared a major determinant of FP knowledge for men, while this was less noticeable for women. Thus, FP communication strategies for refugees should consider gender-specific messages and channels.

\section{Background}

Reproductive health programming is never easy, but provision of effective care to populations affected by conflict and complex emergencies poses special challenges $[1,2]$. The International Conference on Population and Development (Cairo, 1994) and the Fourth World Conference 
on Women (Beijing, 1995) marked a policy shift for both reproductive health and refugee health. The definition of reproductive health became more comprehensive, emphasising the reproductive health needs and rights of the underserved, particularly refugees and internally displaced persons (IDPs) [3-5]. However, despite strengthened international interest and policy frameworks, implementation remains difficult and quality research is minimal [2-4,6-11]. Published studies have concentrated on refugees in more developed countries or stable camp settings.

Globally, refugees and IDPs number over 32.9 million [6], and "reproductive health needs do not disappear upon displacement" [4]. Relief efforts have traditionally focused on acute-phase survival, including HIV prevention and basic emergency obstetric care [7]. However, reproductive health spans relief and development and is essential for long-term survival $[7,8]$. This is particularly true of contraceptive services, whose functioning requires sufficient staff training, counselling skills and supplies, and client trust that service quality is good and supplies will continue. In many camp settings, fertility rates and gender-based violence increase, and maternal and neonatal mortality can be high [7,9]. For example, a World Health Organisation (WHO) study estimated 25-50\% of maternal mortality among refugees as due to unsafe abortion, indicating considerable unmet need for contraception [10]. Implementing agencies now recognise the need to provide contraceptive services. However, despite moves to improve provision, barriers to access and acceptability remain [11-14].

\section{Setting}

From 1989 to 2004, conflicts in Liberia and Sierra Leone displaced over 500,000 people into the Forest Region of neighbouring Guinea [15]. While many Liberians returned home following elections in 1997, civil war in Sierra Leone lasted until 2002. Two major refugee influxes in 1991 and 1997-98 challenged the already weakened Guinean health services, still recovering from disastrous economic and political conditions under Sekou Touré. Following the 1986 Bamako Initiative, Guinea's new government initiated major health sector reforms, encouraging non-governmental agencies to support health service development. Guinea's Ministry of Health responded to refugee health needs through the "Programme d'assistance aux réfugiés Libériens et Sierra Léonais" (PARLS), which soon became an integral part of the health system. Refugees received free treatment from Guinean health services, reimbursed by UNHCR on a fee-for-service basis. However, refugees sometimes perceived government reproductive and sexual health services as deficient. For example, Liberian and Sierra Leonean women had access to family planning (FP) in their home countries, but in
Guinean health centres such services were only introduced in 1992.

In 1995, a group of refugee midwives and interested women organised the 'Reproductive Health Group' (RHG) to improve on the local services available to their fellow refugees in Guéckédou and Kissidougou prefectures. RHG was supported by GTZ (German Technical Cooperation) as a non-governmental organisation (NGO) for refugee health by refugees. It was based on the innovative concept of rallying expertise within refugee communities to address their own sexual and reproductive health needs. RHG mobilised refugee expertise by recruiting and seconding refugee nurses and midwives to local Guinean health facilities, and training refugee lay women to provide reproductive health education, referrals, and contraceptives for the refugee community. RHG used drama groups to reach those less likely to access facilities or RHG facilitators, particularly young people and men. RHG achieved good coverage in Guéckédou and Kissidougou camps (e.g. antenatal services covered $56 \%$ of reproductive-age women). Table 1 summarises the RHG programme, while details are published elsewhere $[14,16]$.

\section{Objectives}

RHG health education and services appeared to reach women effectively. However, workers were concerned about their effectiveness in reaching men and adolescents, which has been found to be problematic elsewhere [12,17-27]. In 1999, a cross-sectional survey was conducted in the refugee population to gather populationlevel data on reproductive health knowledge, attitudes and practices (KAP) for use in strengthening RHG's implementation. The survey collected data on demographics, family planning, sexually transmitted infections (STIs), HIV, antenatal and obstetric care. Study objectives included the assessment of gender or age differences in reproductive health knowledge, attitudes, and practices, which might warrant different approaches for these target groups. This paper addresses gender and age differences in family planning, while STIs are addressed in the companion paper [28].

\section{Methods \\ Study design}

The study this paper is drawn from was a cross-sectional, questionnaire-based interview survey on sexual and reproductive health knowledge, attitudes, and practices. The target population was reproductive-age male and female refugees (15 to 49 ) from an estimated population of 250,000 living in 48 camps across the Forest Region of Guinea, covered by RHG activities for four years. Two planned follow-up surveys were abandoned due to political changes and camp closures. 
Table I: RHG model summary

\begin{tabular}{|c|c|}
\hline Staff & $\begin{array}{l}\text { Management: I coordinator, I deputy coordinator, I youth coordinator. } \\
\text { Support: } 4 \text { supervisors, I data officer, I finance officer, I part-time expatriate advisor (GTZ). } \\
\text { Frontline: } 36 \text { nurse/midwives, } 75 \text { RHG facilitators, I } 4 \text { youth/drama groups. }\end{array}$ \\
\hline Staff training & Safe motherhood, FP, syndromic STI management, HIV prevention. \\
\hline Organisational development & $\begin{array}{l}\text { RHG management team was coached by GTZ in NGO internal governance issues, human resource } \\
\text { management, project management, monitoring and evaluation, health information systems, survey design, } \\
\text { implementation and evaluation. }\end{array}$ \\
\hline Supplies & $\begin{array}{l}\text { Contraceptives: oral, injectible, IUD, condoms, and spermicide supplied through health facilities. } \\
\text { STI drugs: antibiotics for refugees from UNHCR, supplied through health facilities. } \\
\text { Other: transport ( } 2 \text { pickups, } 2 \text { motorbikes), office and audio/visual equipment from GTZ. }\end{array}$ \\
\hline Funding & Approximately USD 164,000 annually (1999). \\
\hline Partners & $\begin{array}{l}\text { GTZ (core funding, organisational development, technical assistance), ARC (training, funding some facilitators), } \\
\text { UNHCR (refugee services coordination, reimbursement of Guinean health services for refugees), Guinean MoH } \\
\text { (health facilities). }\end{array}$ \\
\hline Activities & $\begin{array}{l}\text { Health service based: Female refugee nurses and midwives, seconded to } 28 \text { Guinean health facilities used by } \\
\text { refugees, provided services to refugees and Guineans. } \\
\text { Community based: RHG facilitators provided information, contraceptives (condoms, spermicide) and referral. } \\
\text { Theatre groups and youth clubs provided information and entertainment. }\end{array}$ \\
\hline Goal & $\begin{array}{l}\text { RH professionals and motivated community volunteers enabled to plan, provide and evaluate sexual and } \\
\text { reproductive health services for their fellow refugees. }\end{array}$ \\
\hline Impact & $\begin{array}{l}\text { Improved RH service provision in Forest Region, increased contraceptive usage and STI prevention and } \\
\text { treatment, and became an important actor in the health sector (RHG represented 'best practice' and 'worthy of } \\
\text { study' - WHO consultant [16]). }\end{array}$ \\
\hline
\end{tabular}

Source: von Roenne et al [14].

Sampling was multi-stage. First, 45 clusters of households were randomly selected from the 48 camps, with probability of selection proportional to camp size. Second, a stratified sample of ten men and ten women per cluster (i.e. one eligible man or woman from each of twenty households) was randomly selected from household lists. Sample size was calculated to detect a difference of $10 \%$ versus $20 \%$ between strata of equal size with $80 \%$ power and 95\% confidence interval, accounting for clustering. Participation was voluntary, with no payments other than reimbursement of travel costs made. The study received ethical clearance from the Ministry of Public Health in Guinea and the London School of Hygiene \& Tropical Medicine in the UK.

\section{Data collection}

The questionnaire was designed from instruments used in similar settings and piloted in a camp not included in the study. Several sections covered socio-demographic information, family planning, sexual health, and antenatal care (only for female interviewees). The questionnaire was intended for use in English, and if respondents were not sufficiently fluent, the interviewer translated directly into local language. Questions were read verbatim to ensure reliability, and only rephrased if a respondent did not understand. Interviewers were recruited from the refugee community, and were always the same sex as respondents. A four-day training course and instruction manual were given to all interviewers, covering aspects such as privacy, prompting and translations. Data collection and entry were conducted over four weeks in 1999. Three contact attempts were made before classification as absent and replacement with another household or individual. Data collection and entry were completed within the study period. Data was double-entered in Epi-Info ${ }^{\mathrm{TM}}$ 6, with range and consistency checks to reduce transposition error.

\section{Data analysis}

Analysis was conducted using Stata ${ }^{\circledR} 10.0$. Family planning outcomes were explored for associations with gender and age, using chi-squared tests and Mantel Haenszel odds ratios as appropriate. Potential confounders were determined based on independent association with exposure and outcome variables (i.e. significant at $\mathrm{p}<0.05$ ). Confounders that changed odds ratios by at least $10 \%$ were incorporated into logistic regression models, which accounted for clustering using robust standard errors. 
Effect modifiers were reported individually if they changed the effect of exposure on outcome significantly between strata, as determined by Wald test.

\section{Results}

\section{Demographics}

The response rate exceeded $95 \%$ and the final sample analysed was 889 (445 men and 444 women). Household lists indicated the sexes were represented equally in the study population, and weighting was deemed unnecessary despite stratified sampling by sex. About $60 \%$ of respondents were under age 30, with women significantly younger than men. Most refugees (97\%) were from Sierra Leone, and at the time of interview, more than half had arrived in camp within the past three years (i.e. after $1996)$. Sixty percent of men, but only $29 \%$ of women had received some formal schooling. Almost all (91\%) were sexually experienced. Women were more likely to be married, and 32\% reported their husband as having more than one wife. Women were significantly younger than men at marriage (mean age 16 years versus 24 years for men) and at first intercourse (mean 17 years versus 19 for men). See Table 2 for more.

\section{Family planning}

Table 3 shows family planning knowledge, attitude and practice variables stratified by gender. Family planning as a concept could be explained by most study participants (male 66\%, female 88\%, p < 0.001), but about one-third could not identify a contraceptive method (Table $3 \mathrm{a}$ ). The mean number of modern methods known by women and men were 1.9 and 1.2 respectively, with condoms and pills most recognised. Except for condoms, which more men identified (61\% versus $43 \%$ ), a significantly higher proportion of women identified each contraceptive method $(\mathrm{p}<0.001)$.

Female respondents were almost five times more likely to know about family planning concepts and methods than were male respondents (OR 4.8, robust 95\% confidence interval 2.9-7.9, adjusted for age, ever married and education). Among those with formal education women had three times higher odds of knowing what family planning was (OR 3.0, robust 95\% confidence interval 1.4-6.3, adjusted for age and ever married). Among those with no formal schooling, this difference rose to over six times greater odds (OR 6.4, 3.6-11.1, adjusted for age and ever married). Although the association was only weakly significant (Wald test $\mathrm{p}$-value $=0.07$ ), this suggests that formal education increased the likelihood that men would know about family planning concepts, reducing the knowledge gap between the genders.

RHG facilitators were cited as the main family planning information source for respondents who knew about fam- ily planning $(67 \%)$, though men and women appeared to access health information differently $(\mathrm{p}<0.01)$. While $91 \%$ of women and $86 \%$ of men got their health information from RHG staff or health facilities, men were more likely than women to get information from friends, radio, and RHG dramas (15\% versus $8 \%$ ).

More than $70 \%$ of men and about $90 \%$ of women approved of couples using family planning and of RHG facilitators providing information (Table 3b). However, over $40 \%$ of respondents reported never having discussed family planning with their partners. Forty-three percent of respondents considered that girls should receive family planning information before age 15 , while only $16 \%$ felt this to be appropriate for boys. Women responded significantly more positively to attitude questions than did men ( $\mathrm{p}<0.001)$, but almost a quarter of women reported not knowing their partner's attitude to family planning. Among respondents who knew what family planning was, women were more than eight times more likely than men were to approve of couples using contraception (OR 8.7, 3.8-20.0, adjusted for education and partner approval of family planning).

More than half of respondents reported never having used modern contraception, and only a quarter identified themselves as current users (Table 3c). Condoms, oral contraceptives, and injections were the most popular. Over $75 \%$ of users obtained contraceptives from health facilities. The three main reasons users chose a particular contraceptive source were related to service quality (i.e. privacy, staff competence, staff friendliness). Both women $(80 \%)$ and men $(63 \%)$ reported main reasons for not using contraceptives as 'fertility related' (e.g. abstaining, pregnant, lactating, unable or trying to conceive). Opposition to contraceptive use was reported by $24 \%$ of men versus $8 \%$ of women $(\mathrm{p}<0.001)$. Of those opposed to using contraception, 55\% of men and 26\% of women, predominantly Muslims, reported this as due to religion $(p=0.02)$. Among current non-users, odds of expected future contraceptive use were approximately twice as high for women as men (OR 2.19, 1.4-3.5, adjusted for age, education, and ever married).

Over $90 \%$ of respondents knew where to access contraceptives, with women slightly more knowledgeable about were to get the pill. Women and men identified at least one correct source for an average of 3.6 and 2.5 contraceptive methods respectively (i.e. condom, pill, injection, IUD, spermicide).

Knowledge of family planning as a concept and approval of couples using family planning did not differ significantly between respondents who were younger or older than 20 years, though knowledge was slightly better 
Table 2: Demographic characteristics stratified by gender

\begin{tabular}{|c|c|c|c|c|}
\hline Variable & Category & Male (\%) & Female (\%) & $\mathbf{X}^{2} \mathrm{p}$-value \\
\hline All respondents: & & $445(100)$ & $444(100)$ & \\
\hline \multirow{4}{*}{ Age } & $15-19$ & $103(23)$ & $104(23)$ & \\
\hline & $20-29$ & $|4|(32)$ & $189(43)$ & \\
\hline & $30-39$ & $140(31)$ & $118(27)$ & \\
\hline & $40-49$ & $61(14)$ & $33(7)$ & 0.001 \\
\hline \multirow[t]{3}{*}{ Country of origin } & Sierra Leone & $436(98)$ & $432(97)$ & \\
\hline & Liberia & $7(2)$ & $12(3)$ & \\
\hline & Other & $2(0)$ & $0(0)$ & 0.19 \\
\hline \multirow{2}{*}{ Arrival in camp } & Before 1996 & $202(45)$ & $188(42)$ & \\
\hline & 1996 or later & $243(55)$ & $256(58)$ & 0.36 \\
\hline \multirow[t]{2}{*}{ Education } & No formal education & $|8|(4 \mid)$ & $316(7 I)$ & \\
\hline & Some formal education & $264(59)$ & $128(29)$ & $<0.001$ \\
\hline \multirow[t]{3}{*}{ Religion } & Catholic & $82(18)$ & $88(20)$ & \\
\hline & Protestant & $173(39)$ & $184(4 I)$ & \\
\hline & Muslim & $190(43)$ & $172(39)$ & 0.49 \\
\hline \multirow[t]{4}{*}{ Age at first penetrative sex } & 15 years or less & $113(25)$ & $228(5 \mathrm{I})$ & \\
\hline & 16 years or older & $269(61)$ & $185(42)$ & \\
\hline & Unknown & $10(2)$ & $5(1)$ & \\
\hline & Never & $53(12)$ & $26(6)$ & $<0.001$ \\
\hline \multirow[t]{3}{*}{ Marital status } & Never married & $170(38)$ & $69(16)$ & \\
\hline & Currently married & $251(56)$ & $320(72)$ & $<0.001$ \\
\hline & Widowed/Separated & $24(6)$ & $55(12)$ & \\
\hline \multirow[t]{2}{*}{ Risk of unplanned pregnancy* } & No & $|4|(32)$ & $132(30)$ & \\
\hline & Yes & $304(68)$ & $312(70)$ & 0.53 \\
\hline Ever married respondents & & $n=275(100)$ & $n=375(100)$ & \\
\hline Polygyny & Respondent or husband has other wife/wives & $58(21)$ & $120(32)$ & 0.002 \\
\hline Residence of partner & Living together in camp & $237(86)$ & $275(73)$ & $<0.001$ \\
\hline \multirow[t]{4}{*}{ Age at marriage ${ }^{+}[29]$} & 10 or under & $0(0)$ & $12(3)$ & \\
\hline & $11-17$ & $16(6)$ & $265(7 I)$ & \\
\hline & $18-29$ & $220(80)$ & $96(26)$ & \\
\hline & $30+$ & $39(14)$ & I (0) & $<0.001$ \\
\hline Female respondents & & -- & $n=444(100)$ & \\
\hline \multirow[t]{2}{*}{ Parity } & Nulliparous & -- & $84(19)$ & \\
\hline & Parous & -- & $360(81)$ & -- \\
\hline Parous female respondents & & & $n=360(100)$ & \\
\hline \multirow[t]{3}{*}{ Living children (women) } & None & -- & $36(10)$ & \\
\hline & I-3 children living in household & -- & $258(72)$ & \\
\hline & 4-8 children living in household & -- & $66(18)$ & -- \\
\hline
\end{tabular}

* Those considered at risk for unplanned pregnancy were all those who were between $15-45$, had a partner living in camp, reported no contraceptive use, and were not trying to have a child. ${ }^{+}$Based on WHO definition of adolescence (10-18). 
Table 3: Family planning knowledge, attitudes and reported practices, by gender

\begin{tabular}{|c|c|c|c|c|}
\hline Variables & Category & Male (\%) & Female (\%) & $X^{2} p$-value \\
\hline \multicolumn{5}{|l|}{ a) Knowledge } \\
\hline All respondents: & & $n=445(100)$ & $n=444(100)$ & \\
\hline \multirow[t]{2}{*}{ Can explain FP } & Yes & $294(66)$ & $389(88)$ & \\
\hline & Not sure & $151(34)$ & $55(12)$ & $<0.001$ \\
\hline \multirow[t]{3}{*}{ No. of FP methods known (excluding traditional methods) } & None & $144(32)$ & $132(30)$ & \\
\hline & $1-2$ methods & $241(54)$ & $159(36)$ & \\
\hline & $3-5$ methods & $60(14)$ & $153(34)$ & $<0.001$ \\
\hline \multirow[t]{6}{*}{ Methods identified $\underline{w} / 0$ probing (multiple answers possible) } & Condom & $269(60)$ & $192(43)$ & $<0.001$ \\
\hline & Pill & $168(38)$ & $272(61)$ & $<0.001$ \\
\hline & Injection & $68(15)$ & $206(46)$ & $<0.001$ \\
\hline & Spermicide & $13(3)$ & $85(19)$ & $<0.001$ \\
\hline & IUD & $19(4)$ & $77(17)$ & $<0.001$ \\
\hline & Other (i.e. traditional methods) & $49(11)$ & $77(17)$ & 0.23 \\
\hline \multirow[t]{5}{*}{ Methods identified with probing (multiple answers possible) } & Condom & $407(91)$ & $404(91)$ & 0.8 \\
\hline & Pill & $321(72)$ & $406(91)$ & $<0.001$ \\
\hline & Injection & $250(56)$ & $373(84)$ & $<0.001$ \\
\hline & Spermicide & $100(22)$ & $211(48)$ & $<0.001$ \\
\hline & IUD & $110(25)$ & $228(5 \mathrm{I})$ & $<0.001$ \\
\hline Respondents who explained FP & & $n=294(100)$ & $n=389(100)$ & \\
\hline \multirow[t]{6}{*}{ Key FP information source } & RHG facilitators & $197(67)$ & $262(67)$ & \\
\hline & Health workers & $55(19)$ & $95(24)$ & \\
\hline & Friends and family & $17(6)$ & $20(5)$ & \\
\hline & Drama groups & $14(5)$ & II (3) & \\
\hline & Radio & $6(2)$ & $0(0)$ & \\
\hline & Other/Unknown & $5(2)$ & $I(0)$ & 0.006 \\
\hline b) Attitude & Category & Male & Female & $x^{2} p$-value \\
\hline All respondents & & $n=445(100)$ & $n=444(100)$ & \\
\hline \multirow[t]{3}{*}{ Attitude to couples using FP } & Approve & $326(73)$ & $396(89)$ & \\
\hline & Disapprove & $95(21)$ & $40(9)$ & \\
\hline & Don't know & $24(5)$ & $8(2)$ & $<0.001$ \\
\hline \multirow[t]{3}{*}{ Attitude to RHG facilitators providing FP info } & Approve & $334(75)$ & $405(91)$ & \\
\hline & Disapprove & $91(20)$ & $33(7)$ & \\
\hline & Don't know & $20(5)$ & $6(2)$ & $<0.001$ \\
\hline \multirow[t]{4}{*}{ Attitude to FP teaching (to boys) } & Before age 15 & $59(13)$ & $84(19)$ & \\
\hline & Around age 15 & $155(35)$ & $200(45)$ & \\
\hline & Later than age 15 & $120(27)$ & $102(23)$ & \\
\hline & Disapprove/Don't know & III (25) & $58(13)$ & $<0.001$ \\
\hline \multirow[t]{4}{*}{ Attitude to FP teaching (to girls) } & Before age 15 & $158(36)$ & $223(50)$ & \\
\hline & Around age 15 & III (25) & $117(26)$ & \\
\hline & Later than age 15 & $66(15)$ & $50(\mathrm{II})$ & \\
\hline & Disapprove/Don't know & $110(25)$ & $54(12)$ & $<0.001$ \\
\hline Respondents currently with partner & & $n=25 I(100)$ & $n=320(100)$ & \\
\hline \multirow[t]{2}{*}{ Partner's attitude to couples using FP } & Partner approves & $163(65)$ & $190(59)$ & \\
\hline & Partner disapproves & $60(24)$ & $54(17)^{\prime}$ & \\
\hline
\end{tabular}


Table 3: Family planning knowledge, attitudes and reported practices, by gender (Continued)

\begin{tabular}{|c|c|c|c|c|}
\hline & Don't know partner's attitude & $28(\mathrm{II})$ & $76(24)$ & $<0.001$ \\
\hline c) Practice & Category & Male & Female & $\mathbf{X}^{2} \mathrm{p}$-value \\
\hline All respondents & & $n=445(100)$ & $n=444(100)$ & \\
\hline \multirow[t]{3}{*}{ Reported use of contraception } & Never & $260(58)$ & $25 I(57)$ & \\
\hline & Past & $78(18)$ & $77(17)$ & \\
\hline & Current & $107(24)$ & $116(26)$ & 0.77 \\
\hline \multirow[t]{5}{*}{ Use by respondent/partner (multiple answers possible) } & Ever used condoms & $164(37)$ & $4 \mathrm{I}(9)$ & $<0.001$ \\
\hline & Ever used pills & $71(16)$ & $116(26)$ & $<0.001$ \\
\hline & Ever used injections & $25(6)$ & $70(16)$ & $<0.001$ \\
\hline & Ever used spermicides & $12(3)$ & $17(4)$ & $<0.001$ \\
\hline & Ever used IUDs & $\mathrm{I}(0)$ & $5(1)$ & $<0.001$ \\
\hline \multirow[t]{5}{*}{ Contraceptives currently used (multiple answers possible) } & Condoms & $85(19)$ & $14(3)$ & $<0.001$ \\
\hline & Pills & $32(7)$ & $59(13)$ & $<0.001$ \\
\hline & Injections & $12(3)$ & $43(10)$ & $<0.001$ \\
\hline & Spermicide & $0(0)$ & $2(0)$ & -- \\
\hline & IUD & $0(0)$ & $0(0)$ & -- \\
\hline Respondents currently with partner & & $n=251(100)$ & $n=320(100)$ & \\
\hline \multirow[t]{3}{*}{ Discussion of FP with partner } & Never & $108(43)$ & $143(45)$ & \\
\hline & $1-2$ times in last 12 months & $68(27)$ & $98(30)$ & \\
\hline & More than twice in last 12 months & $75(30)$ & $79(25)$ & 0.35 \\
\hline Current users & & $n=107(100)$ & $n=1 / 6(100)$ & \\
\hline \multirow[t]{3}{*}{ Where current users access FP } & Health post/Clinic & $68(64)$ & $106(92)$ & \\
\hline & RHG facilitators & $30(28)$ & $5(4)$ & \\
\hline & Any other locations & $9(8)$ & $5(4)$ & $<0.001$ \\
\hline \multirow[t]{12}{*}{ Why FP source was chosen (multiple answers) } & Quality-more privacy & $84(80)$ & $106(91)$ & \\
\hline & Quality-competent staff & $86(82)$ & $97(84)$ & \\
\hline & Quality-friendly staff & $82(78)$ & $94(81)$ & \\
\hline & Cost-cheaper & $75(7 I)$ & $99(85)$ & \\
\hline & Convenience-closer to home & $73(70)$ & $71(6 I)$ & \\
\hline & Quality-better product & $65(62)$ & $75(65)$ & \\
\hline & Convenience-shorter wait & $66(63)$ & $71(6 I)$ & \\
\hline & Quality-cleaner facility & $57(54)$ & $67(58)$ & \\
\hline & Convenience-use other services & $44(42)$ & $80(69)$ & \\
\hline & Quality-only available there & $41(38)$ & $52(45)$ & \\
\hline & Convenience-opening hours & $40(38)$ & $46(40)$ & \\
\hline & Convenience-closer to work/market & $28(27)$ & $28(24)$ & -- \\
\hline Current non-users & & $n=338(100)$ & $n=328(100)$ & \\
\hline \multirow{5}{*}{ Main reason for non-use of modern contraception } & Fertility related* & $213(63)$ & $261(80)$ & \\
\hline & Opposed to use & $82(24)$ & $27(8)$ & \\
\hline & Method related & $22(6)$ & $32(10)$ & \\
\hline & Provider related & $12(4)$ & $7(2)$ & \\
\hline & Lack of knowledge & $9(3)$ & I (0) & $<0.001$ \\
\hline \multirow[t]{3}{*}{ Expected future contraceptive use } & Never & $83(25)$ & $45(14)$ & \\
\hline & Later/Don't know & $206(6 I)$ & $240(73)$ & \\
\hline & Within next 12 months & $49(14)$ & $43(13)$ & 0.001 \\
\hline \multirow[t]{2}{*}{ Current non-users, opposed to FP use } & & $n=82(100)$ & $n=27(100)$ & \\
\hline & Religion opposed (all) & $45(55)$ & $7(26)$ & \\
\hline
\end{tabular}


Table 3: Family planning knowledge, attitudes and reported practices, by gender (Continued)

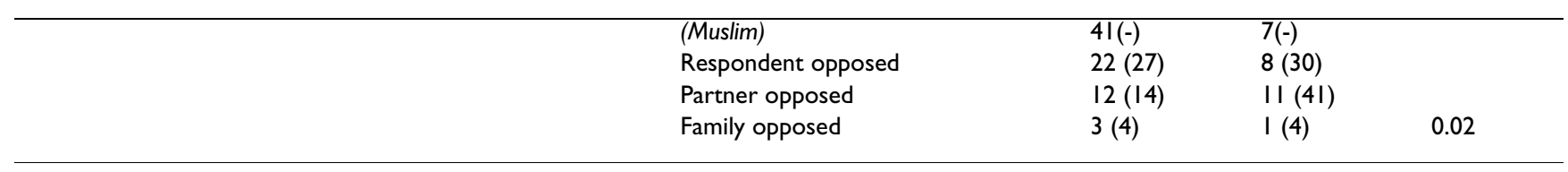

*abstaining, pregnant, lactating, unable or trying to conceive

among older respondents (OR 1.7, 0.8-3.7, adjusted for parity and ever having married) [29]. Contraceptive use was more frequent in the older age group $(\mathrm{OR}=1.5,1.3-$ 1.8 , adjusted for parity and presence of partner in camp).

Those who reported RHG facilitators as their primary information source had non-significantly higher odds of approving of couples using family planning $(\mathrm{OR}=1.8$, $0.7-4.2$, adjusted for parity) and to be current users of contraception $(\mathrm{OR}=1.3,0.7-2.6$, adjusted for parity, education, and partner approval of FP). These respondents also had significantly higher odds of discussing family planning with their partners $(\mathrm{OR}=2.2,1.2-3.8$, adjusted for parity and education).

\section{Discussion \\ Implications}

Comprehensive studies of reproductive health issues among refugees are still relatively rare. This study enabled insight into the influence of gender on family planning knowledge, attitudes and practices in a camp setting. It supports previous findings that men's education helps to increase family planning awareness and attitudes in the way women's life experience (or parity) appears to do [3032]. Additional research is necessary on effective ways of targeting men, and improving their reproductive health knowledge, attitudes, and practices in refugee settings.

Findings indicate that RHG clients knew more about family planning, and were more likely to approve of and use contraceptives. The consistency of positive associations between RHG activities and knowledge, attitude and practices for family planning and sexually transmitted disease indicators [28] suggests that RHG's model (i.e. involving refugee women as active members in a refugee self-help organisation that trained and supported them to provide education and contraceptives to their community) was effective and could possibly be replicated in similar conflict-affected settings $[1,11,14]$.

\section{Limitations}

Cross-sectional studies, while enabling exploration of multiple outcomes and exposures, are limited by potential reverse causality as explanatory and outcome variables are measured at the same point in time (e.g. better family planning knowledge may result from attending RHG activities, or RHG attendance might result from better knowledge). Possible reporting and observer bias was minimised through surveyor training and questionnaire piloting. Residual confounding is possible, due to lack of data on certain variables (e.g. socio-economic status, desired family size, gender-based violence), which could influence family planning choices. Chance was reduced using robust standard errors.

\section{Gender and age differences}

Education appears a major determinant of men's family planning knowledge, but not of women's knowledge or attitudes. Women were younger and less well educated, yet knew more about family planning and contraceptives. Women are often seen as primarily responsible for family planning, and targeted by reproductive health programming [17]. Possibly, the skills men develop through education enable them to seek knowledge and develop informed opinions on topics to which they might not be exposed otherwise. Additional education may change men's attitude towards gender relations. They may want women as partners who are "more than mothers" [14]. Thus, women's greater ability to contribute to household income could be a reason why men expressed support of family planning and girls' education. Men prioritised non-healthcare information sources, such as radio and dramas, supporting suggestions that men tend to access family planning information in non-health settings [2426]. It appeared that women respondents learned about family planning through life experience, as knowledge was not significantly influenced by education or exposure to RHG activities (using "time in camp" as proxy). Parity could be a catalyst, as parous women appeared significantly more knowledgeable about family planning than nulliparous women did $(p<0.001)$. Parity also meant exposure to RHG information during antenatal services.

High reported approval of family planning $(80 \%$ of respondents) did not correspond with current usage (25\%). Main reasons reported for non-use were fertility related $(71 \%)$. However, usage was much higher than typical for West Africa. UN estimated use of current modern contraceptives for 16 West African countries was $7.9 \%$, with Sierra Leone and Guinea at 3.9\% and $4.1 \%$ respectively, while RHG's contraceptive coverage was $17 \%$ $[14,27]$. It is difficult to assess whether use was higher in this population because of greater need or better access, but this relatively high coverage supports the value of 
RHG's work. Nonetheless, our findings suggest that there was still considerable unmet need for contraception and risk of unplanned pregnancy (69\%). Interestingly, only $3.5 \%$ of non-users reported the barrier of 'partner opposition' noted in the literature $[19,21,33]$. It is worth noting that respondents rated quality issues higher than cost or distance when choosing contraceptive services.

Findings indicate that adolescents knew somewhat less about family planning, and sexually active young people were somewhat less likely to use contraception, than adults [29]. However, while results suggest additional attention should be given to adolescent reproductive health, fewer age than gender related disparities were found.

Analysis indicates disparities in family planning knowledge and approval between men and women refugees. Given that refugee men know significantly less about family planning and accessed information through peer networks and mass media as well as healthcare providers, communication strategies on family planning in refugee settings could have greater reach with gender-specific messages and communication channels $[17,18,26]$. The international community should support operational research, involving knowledgeable members of the refugee community, on the best methods of supporting men's utilisation of reproductive health and family planning services within their communities [20,22,23].

\section{Competing interests}

The authors declare they have no competing interests.

\section{Authors' contributions}

$\mathrm{NH}$ analysed the data and drafted the paper, contributed to data interpretation, and gave final approval of the version for publication. SK and YS contributed to conception and design, acquisition of data, and reviewing the paper. AvR conceived the study, and contributed to design, data interpretation, and reviewing the paper. DB contributed to design, data interpretation, and reviewing the paper. $\mathrm{CN}$ contributed to analysis and data interpretation, and drafting the paper. MC contributed to analysis, data interpretation, and critical revision of the paper. $\mathrm{MB}$ designed the study, contributed to acquisition, analysis and interpretation of data, and critical revision of the paper. All authors approved the version to be published.

\section{Acknowledgements}

We wish to acknowledge the cooperation and kindness of interviewees, without whom this research would not have been possible. Thanks to local staff and workers, particularly data manager and field supervisors. We wish to acknowledge local authorities, GTZ Guinea and UNHCR for their support, and GTZ for providing funding. Special thanks to John Cleland (LSHTM) for reviewing an earlier version of this paper and to Simon Cousens (LSHTM) for assistance with regression analysis.

\section{References}

I. McGinn T, Purdin S: Editorial: Reproductive health and conflict: looking back and moving ahead. Disasters 2004, 28:235-238.

2. McGinn T: Reproductive health of war-affected populations: what do we know? International Family Planning Perspectives 2000, 26: $174-180$.

3. Burns K, Male S, Pierotti D: The Reproductive Health of Refugees. International Family Planning Perspectives 2000, 26:16I.

4. Schreck L: Turning point: $\mathbf{A}$ special report on the refugee reproductive health field. International Family Planning Perspectives 2000, 26:162-166.

5. Alcala M: Action for the 2 Ist Century: Reproductive Health and Rights for All. ICPD 1994.

6. UNHCR: 2006 Global Trends: Refugees, Asylum-seekers, Returnees, Internally Displaced and Stateless Persons. Geneva: Division of Operational Services, Field Information and Coordination Support Section; 2006.

7. Ogata S: Refugee women: the forgotten half. Our Planet 1995, 7:19-22.

8. Kollie S, von Roenne F, Blankhart D: Readers' Forum: Humanitarian assistance should include aspects of sexuality. Bulletin of the WHO 1999, 77:1020.

9. Bartlett LA, Jamieson DJ, Kahn T, Sultana M, Wilson HG, Duerr A: Maternal mortality among Afghan refugees in Pakistan, 1999-2000. Lancet 2002, 359:643-649.

10. Cohen S: The reproductive health needs of refugees: emerging consensus attracts predictable controversy. Guttmacher Rep Public Policy 1998, I: 10-12.

II. IAWG: Inter-agency global evaluation of reproductive health services for refugees and internally displaced persons. Geneva: UNHCR; 2004.

12. Degni F, Koivusilta L, Ojanlatva A: Attitudes towards and perceptions about contraceptive use among married refugee women of Somali descent living in Finland. Eur J Contracept Reprod Health Care 2006, I I:190-196.

13. Whelan A, Blogg J: 'Halfway people': Refugee views of reproductive health services. Global Public Health 2007, 2:373-394.

14. von Roenne A, Von Roenne F, Kollie S, Swaray Y, Sondorp E, Borchert M: Reproductive Health Services for Refugees by Refugees: An example from Guinea. Disasters in press.

15. Van Damme W, De Brouwere V, Boelaert M, Van Lerberghe W: Effects of a refugee-assistance programme on host population in Guinea as measured by obstetric interventions. Lancet 1998, 35 I:1609-1613.

16. Msuya D: Report on Assessment of Reproductive Health Services for Adolescent Refugees in Guinea's Forest Region. WHO 1999

17. Collumbien M, Hawkes S: Missing messages: does the reproductive health approach respond to men's sexual health needs? Culture, Health \& Sexuality 2000, 2:135-150.

18. Chikamata $D$ : Male needs and responsibilities in family planning and reproductive health. Plan Parent Chall 1996, 2:8-10.

19. Donati $S$, Hamam R, Medda E: Family planning KAP survey in Gaza. Soc Sci Med 2000, 50:84I-849.

20. Hossain MB, Phillips JF, Mozumder AB: The effect of husbands fertility preferences on couples' reproductive behaviour in rural bangladesh. J Biosoc Sci 2007, 39:745-757.

21. Kaggwa EB, Diop N, Storey JD: The role of individual and community normative factors: a multilevel analysis of contraceptive use among women in union in Mali. Int Fam Plan Perspect 2008, 34:79-88

22. Mullany BC, Becker S, Hindin MJ: The impact of including husbands in antenatal health education services on maternal health practices in urban Nepal: results from a randomized controlled trial. Health Educ Res 2007, 22:166-176.

23. Mumtaz Z, Salway SM: Gender, pregnancy and the uptake of antenatal care services in Pakistan. Sociol Health Illn 2007, 29: I-26.

24. Odu OO, ljadunola KT, Komolafe JO, Adebimpe WT: Men's knowledge of and attitude with respect to family planning in a suburban Nigerian community. Niger J Med 2006, I5:260-265.

25. Sadeghipour Roudsari HR, Sherafat-Kazemzadeh R, Rezaeie M, Derakhshan M: Reproductive health knowledge, attitudes and practices of Iranian and Afghan men in Tehran Province. East Mediterr Health J 2006, I 2:862-872. 
26. Sternberg $\mathrm{P}$, Hubley J: Evaluating men's involvement as a strategy in sexual and reproductive health promotion. Health Promotion International 2004, 19:389-396.

27. UN Population Division: World Contraceptive Use 2003. United Nations Department of Economic and Social Affairs; 2004.

28. Chen M, von Roenne A, Souare $Y$, von Roenne F, Ekirapa A, Howard $\mathrm{N}$, Borchert M: Reproductive health services for refugees by refugees in Guinea II: sexually transmitted infections. Conflict $\&$ Health in press.

29. UNICEF: Innocenti Digest No 7. Early Marriage: Child Spouses. Edited by: Hawke A. Geneva: Innocenti Research Centre; 2001.

30. Chen J, Smith KB, Morrow S, Glasier A, Cheng L: The acceptability of combined oral hormonal contraceptives in Shanghai, People's Republic of China. Contraception 2003, 67:28I-285.

31. Radecki SE, Beckman LJ: Contraceptive risk-taking in a medically-underserved, low-income population. Women Health 1994, $21:$ I-I5.

32. Wall EM: Valued outcomes in the selection of a contraceptive method. West J Med 1984, I 4 I:335-338.

33. van Damme W, De Boelaert M, De Brouwere $V$, van Lerberghe $W$ : Effects of refugee-assistance programmes on host population in Guinea as measured by obstetric interventions. Lancet 1998, 35 I:1609-1603.

Publish with Bio Med Central and every scientist can read your work free of charge

"BioMed Central will be the most significant development for disseminating the results of biomedical research in our lifetime. "

Sir Paul Nurse, Cancer Research UK

Your research papers will be:

- available free of charge to the entire biomedical community

- peer reviewed and published immediately upon acceptance

- cited in PubMed and archived on PubMed Central

- yours - you keep the copyright 